\title{
Do pioneirismo brasileiro da pesquisa em arte ao fenômeno mundial da "artistic research"
}

[ From the pioneering nature of Brazilian "pesquisa em arte" to the worldwide phenomenon of artistic research

\section{Vagner Godói ${ }^{\mathrm{x}}$}

RESUMO - O pioneirismo em defesas de produção artística do Programa de PósGraduação em Artes Visuais da Escola de Comunicações e Artes da Universidade de São Paulo (PPGAV/ECA/USP), criado em I974, e o grande número de artistas-pesquisadores nos diversos programas que atualmente contemplam a pesquisa do artista colocam o caso brasileiro como um dos primeiros e mais consistentes do mundo, ao lado dos exemplos britânico e japonês. O propósito deste artigo é aproximar o pioneirismo brasileiro da pesquisa em arte do fenômeno recente da "artistic research”. • PALAVRAS-CHAVE - Reforma Universitária; ECA/USP; pesquisa artística.

\begin{abstract}
- ABSTRACT - The pioneering nature of the studies on artistic production in the Programa de Pós-Graduação em Artes Visuais da Escola de Comunicações e Artes da Universidade de São Paulo (PPGAV/ECA/USP), created in I974, and the large number of artist-researchers in the various programs currently developing artist research, make the Brazilian case one of the first and more consistent in the world, next to the British and Japanese examples. The purpose of this paper is to bring the pioneering nature of Brazilian "pesquisa em arte" closer to the recent phenomenon of artistic research. - KEYWORDS - University Reform; ECA/USP; artistic research.
\end{abstract}

Recebido em I8 de julho de 2020

Aprovado em 3I de maio de 2021

GODÓI, Vagner. Do pioneirismo brasileiro da pesquisa em arte ao fenômeno mundial da "artistic research”. Revista do Instituto de Estudos Brasileiros, Brasil, n. 79, p. 53-68, ago. 202I.
(c) $(1) \Theta$
DOI: https://doi.org/Io.II6o6/issn.23I6-90IX.vIi79p53-68

I Universidade Estadual Paulista Júlio de Mesquita Filho (Unesp, Franca, SP, Brasil). 


\section{INSTITUCIONALIZAÇÃo DA PESQUISA NO BRASIL}

No Brasil, a institucionalização da pesquisa do artista na universidade é próxima da institucionalização da pesquisa na universidade como um todo. A pesquisa na universidade brasileira se dará de forma completa, com programas de pós-graduação stricto sensu, compreendendo cursos de mestrado e doutorado, tal como conhecemos hoje, somente a partir de I968 com a Reforma Universitária empreendida pela ditadura militar. Logo, em I974, é estabelecido na Escola de Comunicações e Artes da Universidade de São Paulo (ECA/USP) o primeiro programa de pós-graduação próprio para artistas.

No processo de estabelecimento do ensino superior bem como da institucionalização da pesquisa universitária no Brasil, há um entendimento parecido, como se verificou na pesquisa que resultou neste relato² ${ }^{2}$ entre vários autores, tais como Luiz Antônio Cunha (2007), Maria de Lourdes Fávero (2006), Rodrigo Patto Sá Motta (20I4) e Ana Mae Barbosa (2020), de perplexidade e constatação de paradoxo sobre a análise de seu desenvolvimento, uma história de atrasos, desigualdades e interrupções ao lado de processos de modernização e pioneirismo.

Inibido por mais de 300 anos, o ensino superior no Brasil começou depois da transferência temporária da corte portuguesa em I808, com a criação de escolas de caráter profissionalizante: de medicina, de direito, de engenharia militar e de arte. Assim, uma Academia de Belas Artes 3 foi criada no Rio de Janeiro em I8I6, antes mesmo que em Lisboa. Diferentemente de outros exemplos pelo continente americano, as universidades só começaram a ser criadas entre as décadas de I920 e

2 Este texto é uma versão modificada de capítulo da tese de doutorado Funcionamento da obra de pesquisa (GODÓI, 20I8).

3 A Escola Real de Ciências, Artes e Ofícios inaugura o ensino superior de artes no Brasil como desdobramento da vinda dos artistas da Missão Artística Francesa, com nomes como Jean-Baptiste Debret, Nicolas Antoine Taunay e Auguste Henri Victor Grandjean de Montigny. Durante o Império, a escola passou a ser chamada de Academia Imperial das Belas Artes; após a Proclamação da República, de Escola Nacional de Belas Artes e, a partir de I93I, de Escola de Belas Artes (EBA), sendo incorporada pela Universidade do Brasil, hoje Universidade Federal do Rio de Janeiro (UFRJ). 
I930, inicialmente como resultado da união de faculdades existentes, com privilégio na formação de profissionais em vez da pesquisa. É dessa época o começo das discussões, pela comunidade científica, sobre a incorporação da atividade de pesquisa entre as funções da universidade, um debate que não se efetivou em legislação, já que o Estatuto das Universidades Brasileiras, de I93I, estabeleceu doutorados voltados mais para a formação de professores. Discussões sobre a modernização das universidades voltariam a ocorrer somente entre as décadas de I950 e I960, com a criação em I95I tanto do Conselho Nacional de Desenvolvimento Científico e Tecnológico (CNPq) quanto da Coordenação de Aperfeiçoamento de Pessoal de Nível Superior (Capes). Os primeiros programas de pós-graduação contemplando mestrado e doutorado começaram a funcionar em I96I.

Em I965, segundo ano do regime militar que se estenderia ainda por 20 anos, é publicado o parecer CFE n. 977/65, cujo relator foi Newton Sucupira, em que são, pela primeira vez, distinguidos os cursos de especialização daqueles de pós-graduação voltados para a pesquisa no Brasil, passo importante para o desenvolvimento e a expansão dos cursos de mestrado e doutorado pelo país. O parecer teve forte influência do exemplo de pós-graduação norte-americano, que por sua vez foi inspirado no modelo germânico de universidade de pesquisa ${ }^{4}$, e seria fundamental para as grandes mudanças que viriam a seguir. Em I968, há uma grande mobilização de estudantes em manifestações e em vários seminários propostos pela União Nacional dos Estudantes (UNE), onde se discutiam formas mais democráticas de universidade, em tópicos como autonomia universitária, participação dos professores na administração, regime em tempo integral para os professores, entre outros, mas sempre a favor da universidade como produtora de conhecimento. Em resposta, o regime militar criou um grupo de trabalho que deu início à Reforma Universitária de I968. Ao mesmo tempo promulgou o Ato Institucional n. (AI-5), aparato perverso de censura, perseguição, exílio, tortura e morte. A pós-graduação foi um dos pilares dessa reforma, que também efetuou a substituição do sistema de professor catedrático pela estrutura de departamentos e criou a carreira do magistério. Foi estipulado que professores assistentes poderiam ter o título de mestre, mas para chegar ao cargo de professor adjunto, deveriam ter o título de doutor.

\section{Criação da PEsquisa do artista na UniVersidade}

A criação da ECA/USP e do seu Departamento de Artes Plásticas (CAP) se dá nesse período atribulado entre os levantes estudantis favoráveis a uma universidade democrática e a modernização conservadora sobre o ensino e a pesquisa efetuada pelos militares. Antes de sua criação, as artes estavam presentes na USP a partir de disciplinas como história da arte na Faculdade de Arquitetura e Urbanismo (FAU) e na extinta Faculdade de Filosofia, Ciências e Letras (FFCL) (ZANINI, 2008). É curioso

4 O modelo germânico das "universidades de pesquisa", em que pesquisa e ensino se dão de forma integrada, foi implantado por Wilhelm von Humboldt através de uma reforma educacional na então Prússia e aplicado pela primeira vez em I8Io com a fundação da Universidade de Berlim. 
que no decreto de fundação da USP, de I934, estava prevista uma "Escola de Belas Artes" como um de seus institutos oficiais. A escola nunca foi concretizada dessa maneira, embora tenham acontecido várias discussões e tentativas ao longo do século XX (BARBOSA, I994). No momento em que a concretização de um "Instituto de Artes” avançava na USP, o regime militar apoiaria, por seu interesse estratégico em novas tecnologias de comunicação, a Escola de Comunicações Culturais (ECC), criada em I966, ofertando cursos de rádio e televisão, arte dramática, cinema, jornalismo, documentação, relações públicas e biblioteconomia. A partir de I970, depois da insistência e luta de alguns professores, com o impulso da Reforma Universitária e da lei federal que instituiu "artes" como disciplina obrigatória nos currículos de $\mathrm{I}^{\circ} \mathrm{e}$ $2^{\circ}$ graus, a ECC se torna Escola de Comunicações e Artes (ECA), com a implantação dos departamentos de artes plásticas, música e artes cênicas e a oferta do curso de educação rtística a partir de I972. Era um curso generalista curto, de dois anos. Cursando mais dois anos. podia-se optar pela licenciatura plena, com habilitação específica em artes plásticas, artes cênicas, música ou desenho (design). Desde o começo já se previa o desenvolvimento de cursos de mestrado e doutorado, uma vez que foi estabelecido na reforma que professores universitários deveriam ter esses títulos

Se o ensino superior em artes visuais na USP demorou a ser estabelecido, em I974 a ECA vai ser precursora no Brasil na implantação de um programa de pós-graduação em artes visuais, inédito aqui em pesquisas referentes a teoria, crítica, ensino e história da arte, e mundialmente um dos primeiros programas a estabelecer a pesquisa do artista na universidade. Segundo Walter Zanini (I994, p. 488), outro grande responsável por esse pioneirismo, o Departamento de Artes Plásticas da ECA tornou-se referência para os futuros mestrados e doutorados que estavam surgindo. O fato também é citado por Gilbertto Prado (2009, p. 92-93), em seu relato que evidencia o papel da ECA "na disseminação dessa experiência através de seus participantes, alunos e professores de outras universidades" que passaram por lá e, assim, puderam ajudar a desenvolver programas e cursos em outros lugares do Brasil. Prado também fala como foram importantes as presenças de Walter Zanini e dos artistas Regina Silveira e Julio Plaza ${ }^{5}$ para o clima de efervescência, aumentada pela passagem de vários artistas de fora do país convidados a dar aulas na escola, que se constituiu como "um dos grandes centros de produção e difusão de conhecimento, no Brasil e internacionalmente”.

Em I980, já professora do CAP da ECA/USP, Regina Silveira foi a primeira artista a defender uma dissertação no programa de pós-graduação recém-criado. A defesa foi composta da dissertação e de uma exposição apresentadas no Museu de Arte Contemporânea (MAC-Ibirapuera), que naquela época ocupava parte do terceiro piso do Pavilhão da Bienal. Com o título Anamorfas, o trabalho consistiu "em uma produção artística e um 'texto descritivo”" com referências à produção anterior da artista e à história da arte, "através de aspectos conceituais relacionados com a obra,

5 Julio Plaza, Regina Silveira e Walter Zanini também mantiveram, com Donato Ferrari, a escola independente chamada Centro de Estudo Âster, entre I978 e I98I. 
a partir de uma bibliografia"6. A obra de pesquisa desenvolveu-se fundamentada, por exemplo, nas ideias e no "tratamento teórico-prático" de Leonardo da Vinci sobre a "perspectiva artificial", os "múltiplos pontos de vista" de Paolo Ucello, as perspectivas curvilíneas das miniaturas de Jean Fouquet, as "opticeries" de Marcel Duchamp, entre outros. Segundo Regina Silveira (I980, p. 9-Io), a obra de arte Anamorfas não é uma ilustração da discussão sobre a perspectiva, mas a conclusão de um raciocínio visual gerado também pela leitura desses textos e obras. $O$ estudo sobre a perspectiva, iniciado no mestrado, será continuado no doutorado com a pesquisa sobre as "sombras projetadas", uma pesquisa artística que atravessará toda a trajetória da artista. A publicação depositada de Simulacros, que se encontra na Biblioteca da ECA, apresenta-se como um "memorial descritivo da tese de doutorado", fundamentado em vários tratados sobre perspectiva, sobretudo o Tratado de pintura, de Leonardo da Vinci, e inspirado em fontes artísticas como Marcel Duchamp, M. C. Escher, Jan Dibbets, entre outros artistas que são comentados neste texto. A pesquisa, que foi orientada por Wolfgang Pfeiffer e teve o apoio do Conselho Nacional de Desenvolvimento Científico e Tecnológico (CNPq) e da Fundação de Amparo à Pesquisa do Estado de São Paulo (Fapesp), "compreende quatro grupos de trabalhos, constituídos por séries gráficas e instalações ambientais” (SILVEIRA, I984, p. 4). Simulacros (I984) liga-se a Anamorfas (I980), mas sobretudo a outras obras que se desdobraram a partir de então e são apresentadas no memorial descritivo da tese também como simulacros: as séries Enigmas (I98I), Dilatáveis (I982), Símiles (I983) e Topo-Sombras (I983), as instalações Projectio I e II (I984), e In Absentia M.D. (I983), que foi exibida na $I 7^{\mathrm{a}}$ Bienal de São Paulo, edição que teve a curadoria de Walter Zanini. Os textos de Anamorfas e Simulacros são chamados de "texto descritivo" e "memorial descritivo", o que faz essas propostas de mestrado e doutorado serem consideradas pioneiras, pois são focadas na pesquisa de produção artística, um tipo de pesquisa do artista que foi, como vai ser visto a seguir, discutido na Europa nos últimos anos, de um doutorado voltado à produção ou à prática de estúdio.

Regina Silveira ${ }^{7}$ diz que a ideia de defender mestrado e doutorado com obra de arte já estava sendo gestada no momento da criação do CAP no começo dos anos I970. Segundo a artista, a criação da pós-graduação em arte seguiu a movimentação de criação dos outros programas de pós-graduação dessa escola. Outros departamentos, ao criarem seus programas, também estavam incluindo esse tipo de pesquisa de produção ou baseada na prática. Mestrados em rádio e TV, cinema e teatro e artes plásticas surgiram entre I972 e I974, sendo que os doutorados surgiram em I980. Os departamentos da ECA tiveram que se enquadrar no padrão da pós-graduação brasileira para que seus professores obtivessem títulos de mestre e doutor, conforme o que foi estabelecido na Reforma Universitária de I968. A partir daí, um ambiente institucional começou a ser criado, um ambiente propício para que os artistas começassem a fazer seus mestrados e doutorados e pudessem obter bolsas e auxílios financeiros.

Uma das necessidades naquele primeiro momento, princípio do que deveria

6 Depoimento de Regina Silveira a Milton Sogabe (20I4, p. 27) realizado em 30 abril de 2012.

7 Conversa com a artista Regina Silveira realizada em São Paulo, na manhã do dia 26 de junho de 2018. 
ser a pesquisa do artista na universidade, era equiparar a pesquisa artística com a pesquisa acadêmica. Por não haver parâmetros, modelos e definições do que deveria ser a pesquisa artística na universidade - tudo o que se estava pensando e fazendo ali era novo -, Regina Silveira diz que aos poucos os artistas e seus orientadores, geralmente historiadores ou teóricos da arte, tiveram que construir e imaginar algumas regras, estipular alguns padrões, e isso foi se desenvolvendo conforme mais artistas se engajavam na universidade. A artista diz que teve a ajuda de Fredric Litto - na época professor de metodologia científica - para formatar o seu projeto de pesquisa, sendo ele também quem a incentivou a pedir auxílio financeiro para essa pesquisa. A defesa do álbum de gravuras Anamorfas foi apresentada como que cientificamente, diz ela, que teve que começar a desbravar a questão da metodologia científica e trabalhar com os protocolos vindos da ciência.

Antes de Regina Silveira, Renina Katz na FAU/USP havia defendido seus trabalhos com produção artística e memorial descritivo, tanto em seu mestrado de I979, intitulado Matrizes modificadoras do campo plástico, quanto em seu doutorado de I982, intitulado Lugares: I3 litografias originais, algo muito próximo do que estava sendo desenvolvido na ECA como aquilo que deveria ser a pesquisa do artista na universidade. $\mathrm{O}$ artista Claudio Tozzi, sob orientação de Aracy Amaral, também defendeu com obra de arte a sua dissertação de mestrado chamada Obra de arte $e$ sua multiplicação: estudo do processo de reprodução por serigrafia, em I980. Porém, a pesquisa artística universitária acabou tendo um desenvolvimento mais duradouro e consistente no Programa de Artes Visuais da ECA, e depois em várias universidades públicas espalhadas pelo país, em vista da ligação com a graduação específica em arte, pelo número de artistas envolvidos, e também porque um modelo do que deveria ser a pesquisa do artista começou a ser desenvolvido dentro desses programas. Ainda em I980, no programa da ECA, o artista Evandro Carlos Jardim defendeu seu mestrado com uma série de gravuras e um texto intitulado Processos da gravura em metal. Em I98I, Carmela Gross defendeu sua dissertação de mestrado com uma série de desenhos intitulada Projeto para a construção de um céu, exibida no mesmo ano na I $\sigma^{a}$ Bienal de São Paulo. Sua tese de doutorado Pintura/desenho foi defendida no Museu de Arte Contemporânea, em I987. No momento em que as próprias noções de ciência e de pesquisa continuam a ser ampliadas ${ }^{8}$, esses exemplos abrem uma experiência única no Brasil e no mundo à época, que é a possibilidade de um artista, baseado na prática e na teoria, ser pesquisador na universidade, construir metodologias novas e únicas, ter à disposição um programa de pós-graduação para que isso aconteça, obter financiamento de pesquisa e institucionalizar um campo dentro das universidades e com as agências de fomento.

Com o termo "pesquisa em arte", Silvio Zamboni (I998) diferencia pesquisas empreendidas por "artistas que objetivam obter como produto final a obra de arte", em que o artista se "assume como pesquisador", das pesquisas desenvolvidas em outros campos das artes, como história e teoria da arte, arte-educação, restauro,

8 Ver, por exemplo, os estudos de Isabelle Stengers (2002) e Bruno Latour (20I2) de história e filosofia das ciências. 
curadoria etc., que já possuem há mais tempo metodologias próprias, bem como área de atuação mais clara.

Dada a grande dificuldade sobre o tema entre artistas, professores, alunos e os dirigentes de pró-reitorias, e tendo em vista a história e o conhecimento adquirido, Silvio Zamboni defendeu sua tese de doutorado em I993 na ECA/USP, intitulada A pesquisa em arte: um paralelo entre arte e ciência, que veio a ser publicada em I998, preenchendo a lacuna de definição de parâmetros sobre o que é a pesquisa em criação artística. Zamboni diz que havia o Mestrado em Artes na ECA/USP, mas ainda não se sabia o que era a pesquisa em arte, sem referências de outros cursos que pudessem servir de parâmetro. Buscando traçar metodologias para a pesquisa do artista na universidade, o autor mapeou e analisou dissertações e teses prático-teóricas de artistas defendidas na ECA/USP - as que estavam incorporadas na biblioteca à época, de fato o acervo mais antigo da pesquisa em arte no Brasil. O trabalho de Zamboni foi muito importante para explicar e defender o modo de trabalho da pesquisa do artista diante das agências de fomento e dentro das universidades brasileiras, inclusive a fim de imaginar uma metodologia para o fazer artístico mais próxima das ciências, também para tentar criar um processo de trabalho para os artistas-pesquisadores.

No começo dos anos I980, o campo muito vasto das artes, que inclui, além das artes visuais, o teatro e a música, por exemplo, ainda não era oficialmente reconhecido como um campo de pesquisa por nenhuma agência de fomento, e os poucos projetos de pedido de recurso apresentados eram julgados por pesquisadores de outras áreas. Esse panorama começou a se transformar em vista da atuação do ex-funcionário do CNPq, Silvio Zamboni, quando ainda dentro da coordenação de ciências sociais, em oportunidade dada pelo então superintendente de Desenvolvimento Científico, Marcos Formiga, e pelo antropólogo George Zarur, da Coordenadoria de Ciências Humanas, que foi incumbido com a tarefa de formar um embrião da área artística dentro do órgão (ZANINI, 2008, p. 35). Até então, segundo Zamboni (2008, p. 56), alguns poucos trabalhos de artes, incluindo história da arte, eram julgados, mas isso era feito de forma "clandestina”, "precária”, sem os critérios específicos que a área exige, avaliados por pareceristas de comunicação. Zamboni começou a fazer contato com pesquisadores das artes, viajando e fazendo reuniões em muitas escolas e faculdades de várias partes do país, de forma a divulgar as vias de acesso e os modos corretos de solicitação, "despertando a comunidade para a existência desse espaço institucional e para a possibilidade de conseguir auxílio financeiro para desenvolver seus projetos de pesquisa” (ZAMBONI, 2008, p. 56). O autor diz que era necessário, naquele momento, explicar para os artistas, arte-educadores, teóricos e historiadores da arte que eles deveriam pedir, porque os diretos são os mesmos tanto para "os físicos, os químicos, os biólogos”, quanto para eles (ZAMBONI, 2OII). Depois dessas viagens, e com o aumento dos pedidos para bolsas e auxílios, criou-se um Comitê Assessor, agora especializado, para julgar as propostas. A partir disso foi possível negociar com os dirigentes a necessidade da oficialização da área, inclusive para esclarecimento àqueles membros do órgão que consideravam a arte como algo fora da ciência e da pesquisa, com a alegação de que não haveria critérios científicos para definir os projetos a serem aprovados (ZAMBONI, 2008, p. 55). Segundo Walter Zanini (2008, p. 36), havia “o obstáculo de prevenções e objeções de áreas científicas, 
sobretudo a resistência entre as 'exatas', [...] uma opinião pouco ou nada sensível à subjetividade caracterizadora do pensamento artístico”. Após muitas reuniões e não sem divergências, a área de artes foi aprovada pelo CNPq em I984.

A criação da Associação Nacional dos Pesquisadores em Artes Plásticas (ANPAP) ocorreu em I986 como desdobramento desses esforços e através da figura atuante de Silvio Zamboni, que agora tinha também a tarefa de ajudar a estabelecer a subárea de artes visuais ${ }^{9}$ como um campo de pesquisa acadêmica, com parâmetros específicos de "pesquisa em arte" e "pesquisa sobre arte", organizado por seus pesquisadores com interesses diversos. Além do interesse dos artistas, formalizado em um comitê chamado Linguagens Visuais, hoje chamado de Poéticas Artísticas, a ANPAP é dividida, nos termos atuais, em mais outros quatro comitês: História, Teoria e Crítica de Arte; Educação em Artes Visuais; Curadoria; e Patrimônio, Conservação e Restauro. Segundo Zamboni (I998, p. 6), esses outros quatro comitês não tiveram dificuldades no processo de conceituação e caracterização, porém, o mesmo não pode ser dito em relação ao comitê designado à pesquisa dos artistas, até hoje motivo de grandes debates e incertezas no Brasil e no mundo, não só para outros cientistas e acadêmicos, mas também para os próprios artistas e outros pesquisadores da área de artes visuais. Por outro lado, é interessante notar que na criação da associação há o esforço em evidenciar a demarcação de um lugar de pesquisa na universidade e uma regulamentação em órgãos de auxílio financeiro para a pesquisa feita pelo artista. Sobre isso, Walter Zanini (2008, p. 37) diz que: "Muitos debates a marcaram, principalmente ao tratar-se o ponto nevrálgico da formulação da pesquisa pelo artista”. Tanto é assim que são fundadores da ANPAP os artistas Regina Silveira, Anna Bella Geiger, Paulo Bruscky, Diana Domingues, Suzete Venturelli e Anna Barros. Daisy Peccinini (20I7) nos lembra de que o surgimento da ANPAP se deu dois meses depois da instalação da Assembleia Nacional Constituinte, dentro do processo de redemocratização do país, depois de um terrível período para a liberdade de expressão e pensamento, demonstrando que tal momento histórico para as artes estava "em consonância com o Zeitgeist, o espírito do tempo que varria a nação". Desse modo, pode-se dizer que o processo de desenvolvimento da pesquisa artística na universidade brasileira, iniciado no começo dos anos I970, aconteceu como uma batalha subterrânea às imposições repressivas da época, contando não só com os esforços dos críticos, historiadores e teóricos das artes, mas também dos próprios artistas. Peccinini (20I7) continua, dizendo que "A ANPAP nasceu como fruto de uma mística em relação ao desenvolvimento da pesquisa das artes, contaminando em definitivo todos os que se propuseram a trabalhar por sua expansão coletiva, isto é, todos os que participaram e participam da associação".

9 A área é composta também das subáreas da música e das artes cênicas (teatro e dança), que, da mesma maneira que a ANPAP, criaram as suas associações. A Associação Nacional de Pesquisa e Pós-Graduação em Música (ANPPOM) foi criada em I988, e a Associação Brasileira de Pesquisa e Pós-Graduação em Artes Cênicas (Abrace) em I998. 


\section{PIONEIRISMO BRASILEIRO E FENÔMENO RECENTE MUNDIAL DA PESQUISA ARTÍSTICA}

Em que pesem os atrasos e as descontinuidades no desenvolvimento da universidade no Brasil e o iminente perigo que corre pelos últimos retrocessos impostos a todos os campos científicos, nossa pós-graduação pode ser considerada um exemplo de sucesso. A consistência da pesquisa artística no Brasil é resultado de uma batalha história de vários artistas e intelectuais que se uniram para criar um lugar de pesquisa próprio e institucionalizado na universidade. Depois de vários artistas desbravadores, um campo novo de pesquisa foi promovido no Brasil, com o apoio e reconhecimento oficial de agências de fomento. Hoje, no país, I9 universidades públicas ${ }^{\text {Io }}$ mantêm programas de pós-graduação acadêmicos em artes visuais, avaliados com nota acima de 3 pela Capes, com linhas de pesquisa ou áreas de concentração próprias para a produção artística. Em vista desse panorama extenso, pode-se dizer que a pesquisa artística está espalhada pelo país, resultando no crescimento do número de artistas na universidade. Além de tornar as áreas de história, teoria e crítica de arte institucionalmente mais sólidas, o grande ineditismo desses novos programas de pós-graduação em artes visuais foi permitir integrar dentro de sua organização um lugar específico para a pesquisa de criação do artista. Em I993, quando Maria Amélia Bulhões publicou o texto "A pós-graduação e a pesquisa em artes plásticas no Brasil", havia somente um doutorado em artes visuais no Brasil, ainda o curso pioneiro da ECA. No texto, Bulhões (I993) fala sobre a defasagem que existia nas artes visuais, de forma geral, em relação a outros cursos de pós-graduação, ao mesmo tempo que alertava para a necessidade do desenvolvimento da pesquisa do artista em cursos de mestrado e doutorado. Ela diz que os artistas formados, por essa época, não estavam tão interessados em continuar sua formação acadêmica como pesquisadores. Mas a autora diz que havia esforços realizados pela comunidade acadêmica em torno da ANPAP e que os resultados positivos surgiriam em breve. E foi o que aconteceu, tendo em vista a quantidade de exemplos explanados. Fazendo um salto de 25 anos, destaca-se aqui um artigo sobre a pesquisa artística no Brasil publicado em 2018 no Journal for Artistic Research (JAR), dos artistas Gilbertto Prado, Milton Sogabe e Yara Guasque (20I8), que fazem um panorama retrospectivo sobre a formação e o crescimento inicial dos programas de artes visuais. A evolução e a consistência da pesquisa em arte no Brasil são evidenciadas, assim como a demanda

Io Em I4 dessas universidades esses programas são compostos de doutorado e mestrado: USP, Universidade

Estadual de Campinas (Unicamp), Universidade Federal do Rio de Janeiro (UFRJ), Universidade Federal do Rio Grande do Sul (UFRGS), Universidade Estadual Paulista (Unesp), Universidade Federal da Bahia (UFBA), Universidade de Brasília (UnB), Universidade Federal de Minas Gerais (UFMG), Universidade Federal de Goiás (UFG), Universidade do Estado de Santa Catarina (Udesc), Universidade do Estado do Rio de Janeiro (Uerj), Universidade Federal Fluminense (UFF), Universidade Federal de Santa Maria (UFSM) e Universidade Federal do Pará (UFPA); e em cinco apenas mestrado: Universidade do Estado de Minas Gerais (UEMG), Universidade Federal de Pelotas (UFPel), Universidade Federal do Ceará (UFC), Universidade Federal da Paraíba (UFPB) e Universidade Federal de Pernambuco (UFPE). Ver: Resultado da avaliação quadrienal 2017 da Capes e os sites dos programas dessas instituições. 
por formação de um número crescente de artistas e outros profissionais da arte. Segundo Milton Sogabe (20I4, p. 23; 20Io, p. 35), conforme a pesquisa em arte avança na universidade e nos grupos de pesquisa e se transforma em uma das partes de uma área de conhecimento (linguística, letras e artes), começa a aparecer a partir dos anos I980 um novo tipo de artista no Brasil, o artista-pesquisador, que constrói uma carreira acadêmica, engajado em um novo modo de fazer da arte a partir da pesquisa, com os mesmos níveis de exigência de outras áreas do conhecimento, além de ter que cumprir certos protocolos e atividades institucionais que não eram até então atribuídas a um artista. Sogabe faz essa reflexão pontuando a diferença que há entre o artista-pesquisador que surge nos anos I980 e a imagem do artista-professor da década de I970, transformação de perfil que se inicia com o crescimento dos cursos de graduação em educação artística e artes plásticas até a exigência crescente de se dar aulas nas universidades públicas, do diploma de graduação ao título de doutor em arte como pré-requisito. Ricardo Basbaum (2013, p. I93), indicando o aumento do número de artistas contemporâneos que atuam em várias universidades públicas pelo país, diz que "não há como escapar desta máxima: dentro da universidade, o trabalho de arte se transforma em pesquisa e o artista em pesquisador".

O exemplo brasileiro dos doutorados em artes é uma das experiências pioneiras de pesquisa artística mais consistentes e duradouras em todo o mundo, pelo reconhecimento e financiamento das agências de fomento, pelo grande número de doutores formados desde os anos I980 e pela quantidade de programas de pós-graduação estabelecidos. Nas literaturas norte-americana e europeia recentes sobre a pesquisa artística, o caso brasileiro não é considerado como um dos primeiros do mundo e, mesmo no Brasil, não temos muito claro esse nosso feito. James Elkins (20I4, p. I7-32) elaborou uma lista de programas de doutorado para artistas, o que ele chama de "studio-art PhD". Segundo o autor, são muitas as universidades no mundo que oferecem esse tipo de curso. Ele se pergunta qual é a conversa em comum que acontece entre esses programas, se eles compartilham as mesmas preocupações, já que ninguém visitou todas as instituições para se ter um balanço. Elkins (20I4, P. 3-I6) fala sobre dificuldades geográficas, problemas com idiomas, legislação de cada país e falta de comunicação sobre o assunto para que seja estabelecido um painel preciso. O autor cita apenas o Reino Unido e o Japão como cofundadores do que ele chama de "studio-art PhD", pela tradição e pelo nível de desenvolvimento institucional. Outros autores vão citar também os programas australianos do final da década de I980 e os finlandeses, do começo da década de I990.

No Reino Unido as escolas de arte e design começaram a ser integradas, a partir de I966, às antigas instituições politécnicas britânicas, que existiram até I992, quando começaram, por sua vez, a ser transformadas em universidades. A partir da década de 1970 os institutos politécnicos, juntamente com o Council for National Academic Awards (CNAA) ${ }^{\mathrm{II}}$, a antiga autoridade de regulamentação de diplomas, começaram a conferir diplomas de mestrado (MPhil) e doutorado (PhD), sob uma regra que permitia que a defesa fosse composta de parte escrita, com Io-I5 mil palavras para o mestrado,

II O CNAA foi um órgão criado em I960 para a atribuição de títulos de ensino superior de cursos realizados em institutos de ensino não universitários, como os politécnicos. 
e com 20-30 mil palavras para o doutorado, como também de uma apresentação de obra de arte ou trabalho criativo, parte integrante da tese. Segundo Erik Borg (2009, p. 45-87), o primeiro doutorado em artes visuais desenvolvido nesse modelo começou em I975 pelo artista Andrew Stonyer, que teve o apoio do CNAA e foi defendido em I978, com o título de The development of kinetic sculpture by the utilisation of solar energy, contando com a produção de uma escultura cinética, em um coorientação de dois institutos, o Leicester Polytechnic, hoje Montfort University, e a Slade School of Fine Art, de Londres. Para o autor, uma cultura de "practice-led" ou "practice-based PhDs" começou a acontecer, mas não sem passar por um processo complicado, com poucos trabalhos defendidos até I995, por exemplo, com orientadores vindos de outras áreas, da história da arte ou dos estudos culturais, e sem um consenso sobre uma metodologia para área de artes visuais, diferente do design, que se adaptou melhor com desenvolvimentos provenientes das ciências sociais.

No Japão, a Universidade das Artes de Tóquio, conhecida como Geidai, estabeleceu seus programas de doutorado em I977, e as primeiras defesas foram realizadas em I982. A escola conta hoje com três programas: artes visuais, música, e cinema e novos meios. O modelo desenvolvido por lá serviu de referência para outras universidades japonesas, exigindo a defesa de uma parte escrita em conjunto com a produção artística, o que requer habilidades tanto artísticas quanto de pesquisa acadêmica. $O$ fato é notado com surpresa por James Elkins (20I4, p. xiii), que lista 20 universidades japonesas com esse tipo de pós-graduação nas mais diversas áreas artísticas.

$\mathrm{Na}$ Austrália, seguindo reformas do setor universitário ocorridas a partir de I987, várias escolas e institutos de arte foram inseridos institucionalmente nas universidades, o que levou a uma aproximação da arte com a pesquisa e ao consequente acesso aos fluxos de financiamento. Os assim chamados "doutorados em artes criativas" começaram a ser oferecidos em I984 pela Universidade de Wollongong, nas áreas de artes visuais, design Gráfico, música, performance, artes cênicas, escrita criativa e jornalismo, com os esforços do compositor britânico Edward Cowie, então chefe da Escola de Artes (BAKER et al., 2009, p. 27).

Na Finlândia, a Escola de Arte, Design e Arquitetura da Universidade de Aalto concedeu seus primeiros DA (doctor of arts) em I99I, embora o programa tenha sido implementado desde o começo da década de I980. Annette Arlander (2013, p. I52) diz que a Finlândia foi um dos primeiros países europeus a se engajar com a pesquisa artística. Uma das razões para que esse envolvimento tenha ocorrido, segundo ela, é que as escolas de artes na Finlândia já estão integradas ao sistema universitário há mais tempo.

A França, por sua vez, apesar de ter criado programas pioneiros desde os anos I960, vai institucionalizar a pesquisa artística somente a partir dos anos 2000. Até I968, o ensino da arte estava restrito às academias de arte. Diferente do que aconteceu em outros países, essas academias não foram transformadas até hoje, em sua maioria, em institutos universitários. Ocorre que departamentos de artes começaram a ser criados, a partir da reforma universitária que se seguiu às manifestações estudantis de I968, em um processo de reorganização, 
desmembramento ou criação de novas universidades, de adoção de um sistema de créditos e do incentivo à interdisciplinaridade, entre outras mudanças. Um desses primeiros cursos estabelecidos foi o da Université Paris I Panthéon-Sorbonne, dentro da Escola de Artes da Sorbonne. O curso surgiu como um desdobramento do Instituto de Estética e Ciências da Arte (IESA) - fundado por Étienne Souriau em I960 e levado adiante por René Passeron nos anos I970. Esses esforços foram precursores da pesquisa artística desenvolvida por essa universidade, hoje oferecida pelo Programa de Doutorado em Artes Plásticas, Estética e Ciências da Arte (APESA) e do grupo de pesquisas do Instituto ACTE (Pesquisas em Artes, Criações, Teorias e Estética) surgido em 20I2. Segundo Bernard Darras (2012, p. III-II2 - tradução minha), "na França, dois sistemas coexistem: a universidade, que é a herdeira da formação dos professores em educação artística, e as escolas de artes, que são herdeiras do sistema das Belas-Artes”. Por muito tempo somente as universidades podiam ter programas de mestrado e doutorado. Após os mudanças propiciadas pelo Processo de Bolonha, as escolas de arte começaram a ter também esse privilégio, abrindo polos de pesquisa em parceria com as universidades.

Programas de doutorado em artes voltados à produção ou à prática de estúdio viriam a ser discutidos de forma intensa a partir dos anos 2000. As clássicas academias de arte e demais escolas superiores de arte europeias tiveram que incluir um terceiro ciclo de estudo, sendo obrigadas a criar programas de doutorado e a institucionalizar a pesquisa de artista, seguindo a reforma de uniformização do ensino superior europeu empreendida depois da Declaração de Bolonha, um acordo firmado em I999 pela União Europeia ${ }^{\mathrm{I}}$. Daí que a pesquisa do artista na universidade é uma novidade em países como Holanda, Portugal, Áustria, Suécia, Suíça, entre outros. Uma curiosidade é que nos Estados Unidos a pesquisa artística não está institucionalizada na universidade, porque o "master in fine arts" é o título máximo a ser obtido em programas de pós-graduação próprios para artistas, tal como foi estipulado pela College Art Association (CAA) em I977, ocorrendo apenas em alguns casos isolados (JONES, 20I4, p. I07-IO8).

Em 2003 aconteceu em Amsterdã a conferência "Artistic research", a primeira a ser realizada na Europa dentro dessa nova onda de criação de programas de pós-graduação próprios para o artista, marcando o início de um fenômeno no contexto universitário europeu, expandido para outros circuitos artísticos e para outros países. A conferência teve a participação de pesquisadores e curadores como Mika Hannula, Gertrud Sandqvist e Sarat Maharaj e deu origem a um dos

I2 O processo que se desenrolou a partir desse acordo objetivou, além da criação de um Espaço Europeu de Ensino Superior (EEES), que veio a ser instituído em 20Io, a uniformização de titulações e currículos em todas as áreas para que se pudesse estabelecer a comparação entre países, desenvolver critérios únicos de qualidade e metodologias, criar um sistema internacional de transferência de créditos para o intercâmbio entre universidades e instituir um sistema de três ciclos formado por graduação, mestrado e doutorado. 
primeiros livros sobre o tema nessa nova perspectiva ${ }^{\text {I3 }}$. No prólogo do livro, os editores Annette Balkema e Henk Slager (2004, p. 9) dizem que o ensino superior em Arte estava em desenvolvimento naquele período e que era urgente explorar o termo "pesquisa" para a produção artística. Esse rumor, por parte da arte, em torno da palavra-chave "pesquisa" é parte de um processo de reforma universitária no momento em que "conhecimento" e "pesquisa e desenvolvimento" tornam-se denominações estratégicas para os países, em termos econômicos e geopolíticos, em um cenário globalizado e de orientação neoliberal. Henk Borgdorff (20I2, p. 3I-32) fala em 2005 sobre a urgência e o crescimento dos debates, naquele período, em torno de questões ontológicas, epistemológicas, metodológicas e sobre estratégias e políticas educacionais de estabelecimento da pesquisa do artista na universidade, pontuando uma condição totalmente diferente que existia entre as escolas de arte europeias, anteriormente ao processo de Bolonha, e o mundo acadêmico da universidade e dos institutos de pesquisa. Tom Holert (2009) alerta para uma nova preocupação da arte sobre a pesquisa, agora institucionalizada como disciplina acadêmica, e que a escola de arte começa a ser pensada nos termos de uma combinação entre prática artística e prática científica, para além do ensino da arte somente. Essa mudança, diz o autor, sugere "demandas e expectativas da comunidade científica e das agências de fomento em relação aos resultados" no mesmo nível de qualquer pesquisa feita na universidade.

\section{CONSIDERAÇõES FINAIS}

Tanto no Brasil quanto em outros países, a institucionalização da pesquisa do artista aconteceu, em sua maioria, a partir de desdobramentos de reformas no ensino superior. A pesquisa, que não estava institucionalizada e não era uma preocupação das escolas e academias de arte, tem no doutorado em arte o seu momento inaugural, para aqueles que pretendem construir uma carreira acadêmica ou, por exigência institucional, se veem obrigados a conquistar a titulação de doutor para ser professor na universidade. A preocupação sobre o curso de doutorado, visto como uma novidade nos últimos anos em países como Holanda, Áustria, Suécia e Portugal, por exemplo, deve-se ao fato de que a pesquisa artística promovida na academia é ainda inicial nesses países. Olhando a trajetória de países como Inglaterra, Brasil, Japão e Austrália, percebe-se a pesquisa artística em um estágio de maior complexidade, com um grande número de programas de pós-graduação estabelecidos e artistas doutores. Os cursos de mestrado e doutorado são momentos privilegiados da pesquisa artística, mas o percurso é maior, encontra-se além da tese e da dissertação, não se resume ao momento de formação, pois os artistas podem apostar em uma carreira na universidade, ao mesmo tempo como professores e pesquisadores, participando de congressos, publicando livros e artigos, engajando-se em

I3 James Elkins (20I4, p. xiii) situa a coletânea, que foi lançada em 2004, como o primeiro livro desse fenômeno e diz que a bibliografia sobre o que ele chama de "studio-art PhD" disparou em vários países a partir de então, a ponto de uma pessoa apenas não dar conta de tantos livros ou ter a certeza de não estar repetindo ideias já propostas em outros lugares. 
grupos de pesquisa, orientando futuros artistas mestres e doutores, entre outras atividades. Portanto, para acontecer, a pesquisa artística na universidade precisa do reconhecimento manifestado pelo financiamento público constante, com auxílio para grupos de pesquisa e congressos, bolsas para os professores orientadores e demais pesquisadores, mestres e doutores dos programas de pós-graduação em arte. $\mathrm{O}$ artista que começa a cursar um doutorado na universidade e pesquisa pode vir a ser um professor e pesquisador e, por outro lado, ele pode, fora da universidade, levar a sua pesquisa para outros circuitos como museus, galerias de arte, bienais e centros independentes de pesquisa.

Assim, outro aspecto importante desse fenômeno é o interesse renovado dos artistas pela pesquisa e reflexão teórica. Desse modo, a pesquisa artística é um fenômeno da arte sobre o conhecimento que se intensifica a partir dos anos 2000 como uma das características mais expressivas e relevantes da arte contemporânea. Isso pode ser constatado em grandes mostras recentes, como a dOCUMENTA (I3) (20I2); a I Trienal de Tbilisi (20I2), na Geórgia; a 9 Bienal do Mercosul (2013), em Porto Alegre; a $32^{\mathrm{a}}$ Bienal de São Paulo (2016), entre outras. Muitos artistas se reconhecem através da imagem do pesquisador e criam obras de arte em relação a outros campos do conhecimento, tais como história, antropologia, educação, sociologia, estudos culturais, arqueologia, urbanismo e ecologia, em preocupações urgentes da atualidade ${ }^{\mathrm{I} 4}$. Para Henk Borgdorff (20I2, p. 32-33), o fenômeno da pesquisa artística, nascido da transformação das universidades europeias, também é resultado do desenvolvimento da arte contemporânea, que assume a pesquisa como uma de suas temáticas e métodos, e que é proveniente de uma longa tradição modernista sobre o conhecimento e a educação. Borgdorff percebe, do cubismo analítico ao site-specificity, um fenômeno mais amplo de relações da arte com outros campos do conhecimento.

A distância histórica permite ver com mais clareza o notável desenvolvimento e a consistência que a pesquisa em arte, as "poéticas visuais", os mestrados e doutorados em arte alcançaram no Brasil, em uma série de batalhas e também de fatos paradoxais - como ter seu início em pleno regime militar, contradição que se verifica também em uma série admirável de experiências e resistências artísticas do período -, e permite ainda observar como foram criadas as circunstâncias para que a pesquisa do artista na universidade fosse institucionalizada e colocada ao lado de outras áreas do conhecimento e modos de fazer pesquisa com mais tradição e história. Impressiona como esse foi um debate do qual fizeram parte também os próprios artistas, uma demanda que convergiu para as preocupações e os interesses da cena da arte, em um trânsito que proporcionou o desenvolvimento e o direcionamento desse novo tipo de atividade, prática e produção para o artista. Faz parte dessa disposição a boa relação e convivência entre historiadores da arte, artistas e demais profissionais das artes visuais, compartilhando os mesmos circuitos, ambientes, revistas, livros, grupos de pesquisa, congressos. A história da pesquisa artística, localizada ao lado da história da

I4 Entre os vários artistas que trabalham a partir da ideia de pesquisa, podemos citar Hito Steyerl, Ricardo Basbaum, Grada Kilomba, Maria Thereza Alves, Goshka Macuga, Mark Dion, Mabe Bethônico, Ursula Biemann, Carla Zaccagnini, Wendelien van Oldenborgh, Sarah Pierce, Jorge Menna Barreto, Falke Pisano, Nikolaus Gansterer, Simon Fujiwara, Beto Shwafaty, Mariana Castillo Deball, Ícaro Lira, a dupla Bik van der Pol, os grupos Raqs Media Collective e Forensic Architecture, entre outros. 
arte, ainda está por ser escrita, pois revelaria as inúmeras contribuições históricas e sua convergência com a arte contemporânea. Uma história plural e, às vezes, de difícil apreensão, por não ficar restrita aos departamentos de artes visuais ou à própria universidade, por estar dispersa em vários lugares, cenas, circuitos, posições, tradições, poéticas, modos de fazer e pensar, ou seja, como uma história da própria arte.

\section{SOBRE O AUTOR}

VAGNER GODÓI é pós-doutorando no Departamento de História da Universidade Estadual Paulista Júlio de Mesquita Filho (Unesp), campus de Franca (SP), e colaborador do Centro de Investigação e de Estudos em Belas-Artes da Universidade de Lisboa (Cieba-ULisboa) vagner.godoi@unesp.br https://orcid.org/oooo-oooI-8739-540I

\section{REFERÊNCIAS}

ARLANDER, Annette. Artistic research in a Nordic context. In: ROBIN, Nelson (ed.). Practice as research in the arts: principles, protocols, pedagogies, resistances. Londres: Palgrave Macmillan, 20I3, p. I52-I62. BAKER, Su et al. CreativeArtsPhD: future proofing the creative arts in higher education. Project Final Report. Melbourne: University of Melbourne, 2009. Disponível em: https://bit.ly/3eLtBb2. Acesso em: 15 fev. 2018.

BALKEMA, Annette; SLAGER, Henk. Prologue. In: BALKEMA, Annette; SLAGER, Henk (ed.). Artistic Research. Lier en Boog (L\&B), Series of Philosophy of Art and Art Theory, v. I8. Amsterdam: Rodopi, 2004, p. 9-Io. BARBOSA, Ana Mae. Educação artística. Estudos Avançados, v. 8, n. 22, I994, p. 49I-494. Disponível em: https://bit.ly/32ryS4U. Acesso em: 25 jan. 2018.

BARBOSA, Ana Mae. Arte-educação no Brasil: das origens ao modernismo. São Paulo: Perspectiva, 2020.

BASBAUM, Ricardo. O artista como pesquisador. In: BASBAUM, Ricardo. Manual do artista-etc. Rio de Janeiro: Beco do Azougue, 2013, p. I93-20I.

BORG, Erik W. The experience of writing a practice-based thesis in fine art and design. $\mathrm{PhD}$ thesis, University of Leeds, 2009.

BORGDORFF, Henk. The conflict of the faculties: perspectives on artistic research and academia. Leiden: Leiden University Press, 2012.

BULHÕES, Maria Amélia. A pós-graduação e a pesquisa em artes plásticas no Brasil. In: PILLAR, Analice et al. (org.). Pesquisa em artes plásticas. Porto Alegre: UFRGS/ANPAP, I993, p. 93-Io0.

CAPES - Coordenação de Aperfeiçoamento de Pessoal de Nível. Resultado da avaliação quadrienal $20 I 7$. Disponível em: https://bit.ly/2ZEJxqZ. Acesso em: II jun. 2018. 
CUNHA, Luiz Antônio. A universidade temporã: o ensino superior da colônia à era de Vargas. São Paulo: Ed. Unesp, 2007.

DARRAS, Bernard. Pesquisa em arte por ocasião dos doutorados baseados na prática. Um estudo do caso da Universidade de Paris I Sorbonne. ARS, v. Io, n. 20, p. I08-I27, nov. 20I2. Disponível em: https://bit. ly/2DUW8Oz. Acesso em: 23 mai. 2017.

ELKINS, James (ed.). Artists with PhDs: on the new doctoral degree in studio art. Washington DC: New Academia Publishing, 20I4.

FÁVERO, Maria de Lourdes de Albuquerque. A universidade no Brasil: das origens à Reforma Universitária de I968. Educar em Revista, n. 28, p. I7-36, dez. 2006. Disponível em: https://bit.ly/2OwiZ54. Acesso em: I9 fev. 2018.

GODÓI, Vagner. Funcionamento da obra de pesquisa. Tese (Doutorado em História da Arte). Programa de Pós-Graduação Interunidades em Estética e História da Arte, Universidade de São Paulo.

HOLERT, Tom. Art in the Knowledge-based Polis. e-flux journal, n. 3, fev. 2009. Disponível em: https://bit. ly/3ohqJxc. Acesso em: 9 jan. 2016.

JONES, Timothy Emlyn. The PhD in studio art revisited. In: ELKINS, James (ed.). Artists with PhDs: on the new doctoral degree in studio art. Washington DC: New Academia Publishing, 20I4, p. 97-I27.

LATOUR, Bruno. Ciência em ação: como seguir cientistas e engenheiros sociedade afora. São Paulo: Editora UNESP, $20 I 2$.

MOTTA, Rodrigo Patto Sá. As universidades e o regime militar: cultura política brasileira e modernização autoritária. Rio de Janeiro: Zahar, 20I4.

PECCININI, Daisy. Crônica dos primeiros tempos da ANPAP (I985-199æ 20I7). 25 set. 20I7. Disponível em: https://bit.ly/3hgPcK5. Acesso em: 5 out. 2017.

PRADO, Gilbertto. Breve relato da Pós-Graduação em Artes Visuais da ECA/USP. ARS, v. 7, n. I3, 2009, p. 98-IOI. Disponível em: https://bit.ly/3igW6AP. Acesso em: I3 jan. 2018.

PRADO, Gilbertto; SOGABE, Milton Sogabe; GUASQUE, Yara. Breve história - artistic research in Brazil. JAR - Journal for Artistic Research, 20I8. Disponível em: https://bit.ly/3olVYXR. Acesso em: 28 jun. $20 I 8$. SILVEIRA, Regina. Anamorfas. Texto descritivo e apresentação. Dissertação (Mestrado em Poéticas Visuais). Escola de Comunicações e Artes, Universidade de São Paulo, I980.

SILVEIRA, Regina. Simulacros. Tese (Doutorado em Poéticas Visuais). Escola de Comunicações e Artes, Universidade de São Paulo, I984.

SOGABE, Milton. Arte e pesquisa na Academia. In: RIBEIRO, Walmeri; ROCHA, Thereza (ed.). Das artes $e$ seus territórios sensíveis. São Paulo: Intermeios, 20I4, p. 2I-32.

SOGABE, Milton. O ensino de artes e a formação do artista na academia. Marcelina, v. 4, 20Io, p. 29-38. STENGERS, Isabelle. A invenção das ciências modernas. São Paulo: Editora 34, 2002.

ZAMBONI, Silvio. A pesquisa em arte: um paralelo entre artee ciência. Campinas: Editora Autores Associados, I998. ZAMBONI, Silvio. Alguns fragmentos da história das artes plásticas no Brasil (I993-I995). In: OLIVEIRA, Sandra Regina Ramalho e; MAKOWIECKY, Sandra (org.). Uma história da Associação Nacional de Pesquisadores em Artes Plásticas. Florianópolis: Editora da Udesc, 2008, p. 54-63.

ZAMBONI, Silvio. Entrevista com Silvio Zamboni - Parte I. Entrevista concedida a Ana Beatriz Barroso. Youtube, 7 set. 20II. Disponível em: https://youtu.be/jScIIIt4wOg. Acesso em: 27 jan. 2016.

ZANINI, Walter. Arte e história da arte. Estudos Avançados, v. 8, n. 22, I994, p. 487-489, I994. Disponível em: https://bit.ly/2WuTQwo. Acesso em: I7 jan. 2018.

ZANINI, Walter. Elementos sobre a pesquisa em artes plásticas no Brasil e ANPAP (I987-I989). In: OLIVEIRA, Sandra Ramalho e; MAKOWIECKY, Sandra (org.). Uma história da Associação Nacional de Pesquisadores em Artes Plásticas. Florianópolis: Editora da Udesc, 2008, p. 33-38. 